\title{
Research on the Predicaments and Countermeasures for the Modernization of Central Plains' Traditional Culture
}

\author{
Xinyu Li \\ Henan University of Animal Husbandry and Economy, Zhengzhou, Henan, 450044
}

Keywords: predicaments; countermeasures; modernization; Central Plains' traditional culture

\begin{abstract}
Central Plains Culture is a kind of regional culture with a long history and profound origins. It is also a benchmark for the traditional culture of the Chinese nation. The establishment of the Central Plains Economic Zone has provided a strong guarantee for the development of the Central Plains culture. This paper focuses on the inadequacies of the modernization of traditional culture in the Central Plains Economic Zone and gives measures for the modernization of the Central Plains culture.
\end{abstract}

\section{Introduction}

The culture of the Central Plains is indeed long-standing, broad and profound, rich in content, and brilliant. To sum up, there are the following seven characteristics: First, rooted, the Chinese civilization system originated in the Central Plains culture, which is the mother of Chinese culture. The second is dominance. The Central Plains culture represents the mainstream of traditional Chinese culture, especially in the history of China prior to the Northern Song Dynasty. The third is originality. The Central Plains culture is not inherited from certain foreign cultures, but is a culture that has grown up in the Central Plains itself. It has played a pioneering role in the Chinese civilization system. The fourth is openness. The Central Plains culture is inclusive and absorbs the advantages of many surrounding cultures. Because it is located in the Central Plains, plus the political and economic influence of the Central Plains over the past dynasties, it has a very strong influence on the surrounding areas and even China as a whole. Fifth, it is innovative. The history and culture of Central Plains has survived for thousands of years, showing that it has strong vitality. The secret of this vitality lies in its inheritance and innovation [1].

\section{The Dilemma of the Central Plains Culture towards Modernization}

Cultural modernization is influenced by all aspects, such as international factors, geographical location, development status, etc., and is influenced by the origin of culture itself. Since the Southern Song Dynasty has accompanied the national political center away from Henan, Henan has been stuck inland, its location is relatively closed, Henan has long distanced from the national cultural center, education is relatively backward, the overall level of cultural quality of the local residents of the Central Plains is not high; blind optimism, simple and unpretentious, open The lack of activeness and the lack of urgency have caused the Central Plains culture to be puzzled in its march towards modernization. The specific manifestations are as follows.

First, the concept of value-added agriculture and light merchants influence the development of the market economy. The Central Plains culture originated from the agricultural civilization. The agricultural civilization has occupied a long period of time in the history of human development. China's feudal society lasted nearly two thousand years and its development reached the world's leading level. China was established in China from 500 to 1500 AD. The greatest and most prosperous and developed agricultural civilization in the history of civilization, from the point of view of agricultural development in China for more than 2,000 years, the production tools have not undergone much change. For the feudal dynasty, to increase grain production, it is only possible to make a fuss. Increase the area of land and the investment of unit laborers. Nearly two-thousand-years of agricultural civilization has been built in Henan, and its heavy peasant 
ideology has affected so far, and this kind of consciousness is very easy to delineate people within a certain range, making people look short-sighted. Another by-product of agricultural civilization is "light business." The abundant production in the Central Plains region provides favorable geographical conditions for the development of agriculture. The self-sufficient small-scale farming economy of the past millennium has made people happy and weighed heavily. What the society needs today is "no agriculture is unstable, no work is not rich, no business is not available" [2].

Second, the idea is closed and backward, making the Central Plains culture "going out" slowly. Henan is located in landlocked and geographically inland areas. People's ideas are closed and backward, and there is a general tendency to seek stability, not change, to survive without risk, and even to follow the old and not dare to take the lead. Compared with coastal areas, especially those in the coastal overseas Chinese, who dare to dare to take the lead, cross the ocean, start from scratch, and struggle with pioneering spirit, the Central Plains people have some congenital deficiencies, which will inevitably lead to the emergence of the Central Plains culture and the country, Going overseas is facing more difficulties than the culture of the coastal areas. The pace of "going out" of the Central Plains culture is obviously slow.

Third, the level of transformation and innovation of the Central Plains culture to modern culture is not high and competitiveness is not strong. Innovation is the soul of a nation. Cultural innovation is an inevitable requirement for the development of social practice and is an inherent driving force for the development of culture itself. The level of cultural innovation is a determinant of whether culture can "go global" and its competitiveness. The innovation of the Central Plains culture requires critical inheritance traditions, but it must also instill an ethos of the times. The Central Plains culture must overcome the huge obstacles in time and space and realize the conversion of ancient culture to modern culture [3].

Fourth, the lack of contemporary cultural talent in the Central Plains, especially the lack of master figures, weakened the intelligent foundation for the promotion of the soft power of the Central Plains culture. Universities and scientific research institutes are the gathering places for cultural talents. Henan has a lot of deficiencies in this area. There are no more national-level scientific research institutes, no direct key universities under the Ministry of Education, plus talents since the 1990s. The general direction of the country's mobility is to concentrate on the southeast coast and "north, up, and wide", and Henan has basically become a net exporter of talents, especially in the serious shortage of compound cultural talents with higher levels and stronger capabilities. The plight of the shortage of cultural talents has further increased the lack of strong intellectual support for the Central Plains culture.

Fifth, the propaganda of the Central Plains culture was limited and its influence did not reach its due status. Cultural propaganda has a close relationship with cultural influence. Cultural persuasion reaches its influence through propaganda. The mainstream media of Henan (including electronic media) is the main channel for the spread of culture in Central Plains. However, the breadth and depth of its impact in the country and the world are clearly insufficient compared to the developed regions in China. This inevitably limits the expansion of the Central Plains culture and its dissemination.

Due to the origin of the Central Plains culture, the Central Plains culture has always been more emphasis on the construction of agricultural civilization, coupled with the long history of agricultural civilization in our country, which greatly promoted its development, Henan Province due to more than two thousand In the year of the Central Plains culture, the traditional idea of valuing agriculture has not been able to be reversed. With the passage of time, the Central Plains culture has grown stronger and stronger, and people have been fixed in this kind of ideology and culture, and their eyes are short-sighted. on the other hand. The concept of "light business" in agricultural civilization has a great influence on the healthy development of agricultural civilization. The Henan region has relatively abundant resources. The superior geographical conditions are more conducive to the development of the agricultural economy. In the Central Plains region in ancient times, self-support was formed. Self-sufficient human civilization is of utmost importance to the interests of the people. However, in today's society, there has been the formation of 
"non-agricultural instability, no worklessness, no business, no livelihood."

\section{Ways for Central Plains Culture to Modernization}

The concept of improvement and innovation has discarded the old model that hindered the promotion and dissemination of the Central Plains culture, continuously discovers and uses innovative thinking modes, and enables the Central Plains culture to be further promoted and modernized on the basis of the original. At this stage, Azi Central Plains In the region, various large-scale economic construction zones have gradually been built, and they have mainly moved towards the goals and tasks of the "threeizations", mainly including industrialization, urbanization, and agricultural modernization, and will also gradually realize the transition and transformation of economic development. The main direction is the transformation of the agricultural economy to the industrial economy. Then the economic transformation will also lead to the gradual transformation of the culture. In order to innovate ideas and realize the strategy of going out of the Central Plains culture, the most important content is to increase the construction of the Central Plains Economic Zone, which is traditional culture. Integrate with new industrial culture and plan early [4].

The key to people's pursuit of spiritual culture is to promote the traditional culture of their own people. Because spiritual civilization is the most spiritual culture that can get you close to the people and can get everyone's approval, it can resonate with everyone. However, it is relatively backward, but its own value is also stronger, it has its outstanding and shining place, and it has a great spiritual value. The traditional culture of Central Plains is the focus of the content of spiritual civilization, and it is also a more positive response to modern spiritual civilization.

Any civilization in any region is indiscriminately influenced by globalization. For the traditional culture of the Central Plains, it is far from enough to rely on various domestic modern ideas. It needs to combine advanced scientific ideas both at home and abroad. At this stage, even in the country, we can absorb the advanced economic culture and communication era from abroad. Using foreign culture to develop national culture is the future development trend. In the 21st century, people were tempted by utilitarianism and fame. Many Chinese and foreign cultures have begun to lose their bearings and have disappeared. In modern society, these traditional Central Plains cultures should be strengthened to ensure their continued circulation. As already mentioned above, the propaganda of culture and the influence of culture are interrelated and mutually restrictive. Only by making greater propaganda efforts can we avoid the situation of "cultivating people who are not well-versed", and the language of the propaganda can be easily understood.

Increase publicity and spread. Propaganda is a systematic project that involves a series of strategic, tactical and methodological issues throughout the publicity process. The relevant propaganda agencies in the province should be integrated and combined with their own actualities to promote the display of the culture of the Central Plains in order to allow more people to understand and avoid "keeping in the dark". In the method of propaganda, we should pay attention to carriers. In recent years, Henan TV station "Li Yuan Chun" and "Wulin Wind" programs have had a wide range of impacts at home and abroad. Its easy-to-understand, intuitive and direct way has spread Zhong Opera Culture and Wushu Culture. The influence continues to expand. This is a successful case of cultural propaganda. In today's globalization, we talk about the inheritance and development of the Central Plains culture, we need not only to transform the Central Plains culture, but also need to adhere to the Central Plains culture. The Central Plains is the place where the Three Emperors and Five Emperors established their capitals. The Central Plains is the origin of the Chinese civilization. The Central Plains is the source of many Chinese surnames. The Central Plains culture is more of a "culture" and "original culture", and losing its roots is bound to lose its way. Therefore, today's globalization, the protection it cherishes, is to strengthen the protection of ethnic folk and regional culture [5].

\section{Conclusion}

While inheriting the culture of Central Plains, we must vigorously develop advanced culture and 
nurture a modern culture that adapts to the rise of the Central Plains. The construction of the Central Plains Economic Zone and cultural construction are also important contents. On the basis of inheritance, it is necessary to cultivate modern culture that adapts to the rise of the Central Plains and to meet the growing spiritual and cultural needs of the people.

\section{Acknowledgements}

Fund Project: Project of Henan Key Universities for Scientific Research Project Name: "Human Capital Management Practice and Research in Newly-built Universities", Item Number: 17A880008

\section{References}

[1] Yin Huan. Inheritance of Chinese Traditional Culture in the Development of Modern Society [J]. Urban Construction Research, 2016(13).55

[2] Wang Ying. On the Inheritance and Development of Chinese Traditional Culture [J]. Travel Monthly, 2012(05).63

[3] Zhai Shengchuan. Research on the Strategy of Inheriting Outstanding Chinese Traditional Culture in Colleges and Universities under the New Situation [J]. Curriculum Education Research, 2015(01).28

[4] Wang Li. The Inheritance of Chinese Traditional Culture from the Perspective of Memetics[J]. Science and Education, 2014(06).110

[5] Wang Hua. Problems and Countermeasures in the Development of China's Cultural Industry [J]. Journal of Liaoning Administration Institute. 2008(07).25 